\section{Рогожин С.П.}

канд. юрид. наук, доцент, судья Суда по интеллектуальным правам, Москва

e-mail: rsp72@mail.ru

\section{Сазанова С.Л.}

канд. экон. наук, доцент, доцент кафедры институциональной экономики ФГБОУ ВО «Государственный университет управления», Москва e-mail: sazanova@mail.ru

\section{Rogozhin S.P.}

Ph.D. in Law, Associate Professor, Judge of the Court for Intellectual Property Rights, Moscow

e-mail: rsp72@mail.ru

\section{Sazanova S.L.}

Ph.D. in Economics, Associate Professor, Associate Professor of Institutional Economics Chair, FSBEI HE State University of Management, Moscow e-mail: sazanova@mail.ru

\section{Интеллектуальные права собственности: институциональный подход}

\begin{abstract}
Аннотация
Авторы статьи рассматривают интеллектуальные права собственности с двух точек зрения: теории права и институциональной экономической теории. В статье раскрыты содержания понятий «интеллектуальная собственность», «интеллектуальные права» и обоснована необходимость их изучения не только с правовой, но и с экономической точки зрения. Авторы подчеркивают, что институциональная экономика в целом и экономическая теория прав собственности, в частности, обладают огромным потенциалом в изучении как теоретических, так и практических аспектов интеллектуальных прав. По их мнению, именно институциональный подход позволит создать эффективное законодательство в данной области.
\end{abstract}

\section{Ключевые слова:}

права собственности, экономическая теория прав собственности, интеллектуальные права собственности, институт интеллектуальной собственности, трансакционные издержки, интеллектуальные права, интеллектуальная собственность.

\section{Intellectual Property Rights: Institutional Approach}

\begin{abstract}
The authors consider the intellectual property rights from two points of view: legal theory and institutional economical theory. Contents of "intellectual property" and "intellectual rights" concepts have been revealed in this paper, and the necessity of their study has been justified not only from the legal point of view, but also from the economic one. The authors emphasize that the institutional economics in general and the economic theory of property rights, in particular, have a great potential in the study both of theoretical and practical aspects related to intellectual rights. According to the authors, it is the institutional approach which will create an effective legislation in this area.
\end{abstract}

Keywords:

property rights, economic theory of property rights, intellectual property rights, Intellectual Property Institute, transaction costs, intellectual rights, intellectual property.
В современной экономической науке и юриспруденции все чаще используют такие категории, как «интеллектуальные права» и «интеллектуальная собственность». Авторы используют их под определенном углом: экономическим или правовым [2]. Следует отметить, что российская наука имеет богатые традиции исследования интеллектуальной собственности: еще И.Т. Посошков в работе «Книга о скудности и богатстве» (1724) уделял большое внимание «измышленникам» (изобретателям), их вкладу в развитие российской экономики и необходимости поощрения государством изобретательства. Позже, в 1881 г., Н.Н. Салов в докладе на заседании Императорского Русского технического общества указал [10], что в основе общественного прогресса лежит «умственная» собственность как высшая форма частной. Он утверждал, что отнять умственную собственность нельзя, поэтому общество, заинтересованное в прогрессе, должно создавать изобретателю такие условия, при которых ему было бы выгодно эту собственность отдавать обществу.

Развитие института интеллектуальной собственности в современной России настолько опережает становление его нормативной основы, что породило раскол в обществе и среди государств. Э.Я. ВолынецРусеет и К.А. Сидоров указывают, что иногда допускается неточное, а порой ошибочное толкование различных правовых и экономических аспектов, относящихся к выявлению, защите и коммерческой реализации тех или иных видов интеллектуальной собственности: «Понятие интеллектуальной собственности охватывает очень широкий круг объектов, созданных интеллектуальным трудом и отличающихся друг от друга. До настоящего времени продолжаются дискуссии по понятию интеллектуальной собственности, по проблемам ее возникновения, закрепления и использования как создателями, так и теми, кому она передана по договору» [1]. 
Известны миру собственность (вещная) на материальные блага (ценности) и интеллектуальная собственность на нематериальные блага (ценности), которую часть ученых собственностью не признает. А еще - у части юристов стало парадигмой убеждение: собственность - экономическая категория; права собственности - юридическая категория. При этом надо оговориться, что, несмотря на отсутствие в национальном законодательстве легального определения «интеллектуальная собственность», этот термин нельзя понимать буквально как разновидность права собственности. Словосочетание «интеллектуальная собственность» необходимо воспринимать как единое целое, включающее совокупность прав на результаты интеллектуальной деятельности и средства индивидуализации. Это позволяет обеспечивать правильное понимание сущности интеллектуальной собственности.

Сегодня в мире сложилось четкое представление об интеллектуальной собственности как совокупности прав в отношении нематериальных результатов интеллектуальной деятельности человека и средств индивидуализации. В части четвертой Гражданского кодекса Российской Федерации вместо термина «интеллектуальная собственность» для обозначения рассматриваемой разновидности субъективных гражданских прав используется термин «интеллектуальные права». При этом интеллектуальные права подразделены на три подвида (группы): 1) исключительное право, 2) личные неимущественные права и 3) иные интеллектуальные права.

Интеллектуальные права - это набор, комплекс различных гражданских прав, возникающих на ряд объектов гражданского права. Эти объекты, именуемые «интеллектуальная собственность», в настоящее время по российскому законодательству состоят из 16 различных объектов. В то же время наступает такой момент в развитии общественных наук, когда интеллектуальные права и интеллектуальная собственность нуждаются в обновлении, а также научные взгляды на их сущность, подходы к определению ее места и роли в системе социально-экономических отношений. Актуальным в связи с этим является все более развивающийся методологический подход к анализу собственности как к синтетической экономико-правовой категории, который основывается как на принципах традиционной политической экономии, так и на теории прав собственности, развивающейся в рамках современного институционального направления экономической науки.

Именно такой, синтетический, анализ категории собственности позволяет сегодня понять всю важность и сложность проблемы реформирования от- ношений собственности в переходных экономиках, с одной стороны, и найти такие формы и методы наиболее эффективного распределения прав собственности, которые в существенной мере определяют социально-экономический прогресс национальной экономики. Политико-экономическая традиция исследования собственности связывает ее возникновение и развитие со становлением и развитием общественного производства и рассматривает собственность как особого рода отношения между людьми, возникающие в процессе экономической деятельности по поводу присвоения средств и результатов производства. В соответствии с этим собственность в наиболее общем виде может быть определена как исторически определенный способ присвоения людьми благ, необходимых им для потребления или осуществления производственной деятельности.

Вместе с тем в течение достаточно длительного исторического периода исследователи подходили к изучению собственности и с другой - правовой (юридической) стороны, прежде всего через определение прав собственности и образующих его правомочий. В современных условиях данный подход выявил проблему институционализации отношений собственности и ее значимость для эффективного развития рыночных отношений. Взаимосвязь и взамозависимость юридических характеристик и экономического содержания объектов или явлений исключительно точно сформулирована Р. Саватье в работе «Теория обязательств» на примере вещей: «Вещь существует лишь благодаря своей экономической полезности. Но это свойство полезности она приобретает для человека лишь благодаря правам, которыми он обладает в отношении этой вещи. Таким образом, экономическая полезность вещи предполагает соответствующее ее правовое положение. И наоборот, права, относящиеся к вещи, учитывают экономическую оценку ее полезности» [8]. По мере развития общества, появления новых вариантов использования и обращения вещей, формирования новых экономических отношений и механизмов происходят определенные изменения и в трактовке собственности. Однако суть этого понятия остается неизменной: под собственностью понимается право пользоваться и распоряжаться вещами самым неограниченным образом. Что касается элементов, составляющих право собственности, то постепенно складывается представление об этом праве как о единстве трех правомочий: владения, пользования и распоряжения.

Традиционная (классическая) трактовка указанных правомочий, составляющих право собственно- 
сти, сводится к следующему. Владение - это возможность физического контроля над вещью, право непосредственно влиять на ее состояние. Пользование - право на извлечение полезных свойств вещи и полученных благодаря этому результатов. Распоряжение - право на определение юридической судьбы вещи, на отчуждение (полное или частичное), вплоть до уничтожения вещи. Данные правомочия дополняют друг друга, в совокупности образуя само право собственности. В этом смысле оно может рассматриваться как совокупность прав собственности. Говоря об интеллектуальной собственности как экономическом объекте, ее можно определить как распоряжение (монополизм) идеальной субстанцией - знанием (информацией). Правомочия «владение», «пользование» не подходят к знанию в том смысле, что физически обладать идеями нельзя, они могут находиться одновременно в пользовании бесчисленного круга субъектов, а устаревают лишь морально. С теоретической точки зрения вещное содержание правомочий собственности не отражает сути данных отношений. Как известно, владеть, пользоваться, а порой даже распоряжаться принадлежащим собственнику имуществом может любое лицо. Собственник вправе по своему усмотрению передавать другим лицам названные права, оставаясь при этом собственником имущества. Смысл состоит в том, что осуществление любым лицом прав собственника зависит от усмотрения самого собственника, который независим в своих предпочтениях.

Применительно к интеллектуальной собственности можно отметить, что ее объектом признается результат интеллектуальной деятельности (и приравненное к нему средство индивидуализации). При этом интеллектуальная собственность толкуется как отношения по поводу присвоения ее объектов, выраженных в объективной форме, с учетом специфики, обусловленной особенностями формы существования этих объектов и их введения в экономический оборот [3]. Таким образом, права, составляющие в совокупности право интеллектуальной собственности, выступают в качестве правил хозяйственного поведения и вполне подпадают под понятие института в том смысле, в каком это понятие используется представителями институциональной школы в экономической науке: институты - это «...создаваемые людьми рамки, которые структурируют политические, экономические и социальные взаимодействия» [5]. Институты «...представляют собой структуру, которую люди накладывают на свои взаимоотношения, определяя, таким образом, стимулы, наряду с другими ограничениями (бюд- жетными, технологическими и т.д.), очерчивающими границы выбора, а они, в свою очередь, задают рамки функционирования экономики и общества в течение того или иного времени» [4]. Другими словами, институты - это определенные рамки, границы взаимодействия людей, которые создаются с целью необходимым образом структурировать политико-экономические и социальные отношения в обществе [5]. Институты определяют реально действующие правила хозяйственного поведения индивидов и организаций [9]. Поскольку его основу составляют объективные закономерности функционирования экономики, постольку эти правила должны соответствовать и закономерностям развития собственности как присвоения.

Таким образом, понятие «право интеллектуальной собственности» и составляющие его правомочия владения, пользования и распоряжения в совокупности со всей нормативной базой, обеспечивающей их применение в экономической деятельности, представляют собой институты, через которые собственность как присвоение реализуется в реальной хозяйственной практике, создавая стимулы и правила хозяйственного поведения.

Ведущие направления современного институционализма, неоинституциональная и новая институциональная экономика обладают огромным потенциалом экономического анализа интеллектуальной собственности. Основная идея институционализма заключается том, что наиболее продуктивным в изучении собственности и ее экономической роли является не континентальный, а англосаксонский подход. В соответствии с континентальным подходом право собственности является единым и неделимым, а наши вышеизложенные аргументы свидетельствуют, что это не так. Англосаксонский подход рассматривает категорию собственности как набор или «пучок» частичных правомочий («пучок» Оноре), что позволяет решить по меньшей мере две задачи. Во-первых, развивать законодательство в направлении совершенствования спецификации прав собственности; во-вторых, на основе совершенствования законотворчества и правоприменительной практики увеличивать эффективность использования экономических ресурсов, расширяя границы обмена.

Именно понимание собственности как набора одиннадцати исключительных правомочий, предполагающих использование, дробящихся в случае необходимости на более мелкие и не обязательно принадлежащие одному лицу, позволяет рассматривать объект собственности не как вещь, а как право совершать с ним какие-либо действия. Цен- 
ность имеет не сам объект, а возможность распоряжаться им, принимать решения о том, кто и как может извлекать из него полезность [7]. Интеллектуальная собственность применительно к данному подходу представляет собой совокупность исключительных правомочий в отношении результатов интеллектуальной деятельности и приравненных к ним объектов, закрепляемых за конкретным лицом, с одновременным запретом доступа к этим объектам всем иным лицам.

Практический потенциал экономической теории прав собственности в отношении интеллектуальной собственности заключается в возможности анализировать эффективность законодательства с точки зрения согласования экономических интересов хозяйствующих субъектов. Интересный анализ конкретных ситуаций предлагает, например, Р. Познер [6] в работе «Экономический анализ права». Он доказывает, что защита авторских прав (патентное право) стимулирует изобретательскую деятельность, поскольку позволяет изобретателю компенсировать издержки и превратить положительные внешние эффекты создания благ во внутренние. Однако патент не позволяет изобретателю максимизировать полезный эффект, поскольку действие патента ограничено во времени. Альтернатива патенту - коммерческая тайна позволяет решить эту задачу. Коммерческая тайна позволяет изобретателю избежать «издержек и неопределенностей, связанных с получением патента», а также копирования его изобретения конкурентами. Авторское право с точки зрения институционального подхода представляет собой компромисс между патентным правом и правом коммерческой тайны, поскольку имеет огра- ничение во времени (50 лет) и допускает независимое открытие. Различные варианты защиты интеллектуальной собственности призваны создать максимально благоприятные условия для создания инновационных благ и достижения баланса между личными и общественными интересами.

В результате выделения отдельных правомочий в праве собственности, их спецификации, классификации, определения их соотношения с иными правомочиями экономическая теория прав собственности становится развитием и дополнением классической теории собственности как присвоения, создавая систему институциональных форм присвоения. Между этими подходами нет принципиальных расхождений - они отличаются, прежде всего, уровнем абстракции при исследовании отношений собственности.

Традиционный подход отражает реальную роль различных участников общественного производства в деятельном процессе созидания и умножения интеллектуальной собственности. Институциональный подход дает возможность на основе определения вклада участника в результаты интеллектуальной деятельности учесть этот вклад через наделение того или иного субъекта определенным набором правомочий по отношению к созданному продукту.

Таким образом, можно сделать вывод о том, что в эпоху глобализации экономики, активного влияния и взаимодействия правовых и экономических теорий на институт собственности, в частности интеллектуальной, возникает необходимость совместного изучения данной экономико-правовой категории с целью дальнейшего эффективного и рационального развития экономики страны и мира.

\section{Литература}

1. Волынец-Руссет Э.Я. Различные виды интеллектуальной собственности и их отличия [Текст] / Э.Я. Волынец-Руссет, К.А. Сидоров // Внешнеэкономический бюллетень. - 2002. - № 10. - С. 7.

2. Дозорцев В.А. Понятие исключительного права [Текст]/ В.А. Дозорцев // Интеллектуальные права: Понятие. Система. Задачи кодификации. Сборник статей. Исследовательский центр частного права. - М.: Статут, 2003.

3. Кириченко E.A. Институт интеллектуальной собственности: Содержание, формы и проблемы развития [Текст]: автореф. дис. ... канд. экон. наук: 08.00.01 / Е.А. Кириченко. - Кемерово, 2003. - С. 11, 12.

4. Норт Д. Институты и экономический рост: историческое введение [Текст] / Д. Норт // THESIS. - 1993. Вып. 2. - С. 73.

5. Олейник А.Н. Институциональная экономика [Текст]/ А.Н. Олейник. - М.: ИНФРА-М, 2012. - С. 25.

\section{References}

1. Volynets-Russet, E., Sidorov G. Different types of intellectual property and their differences. Foreign Economic Bulletin. 2002, V. 10, p. 7. (in Russian)

2. Dozortsev V. The notion of exclusive rights. Intellectual property rights: The concept. System. The objectives of codification: Digest of articles. Moscow, 2003. (in Russian)

3. Kirichenko E. Institute of Intellectual Property: The content, form and development problems. Doct. Diss. Kemerovo. 2003, pp. 11-12. (in Russian)

4. North D. Institutions and Economic Growth: A historical introduction. THESIS. 1993, V. 2, p. 73. (in Russian)

5. Oleinik A. Institutional Economics. Moscow, 2012, p. 25. (in Russian)

6. Posner R. Economic Analysis of Law. St-Petersburg, 2004, V.1, pp. 51 - 61. (in Russian)

7. Rogozhin S. Intellectual property rights: economic and legal aspects. Institutional Economics: Development, Teaching, 
6. Познер Р. Экономический анализ права [Текст] / Р. Познер. - СПб.: Экономическая школа, 2004. - Т. 1. 524 c. - C. $51-61$

7. Рогожин С.П. Интеллектуальные права: экономикоправовые аспекты [Текст] / С.П. Рогожин. - В кн.: Институциональная экономика: развитие, преподавание. Приложения. Материалы четвертой Международной научной конференции. Государственный университет управления; под ред. Г.Б. Клейнера. - М.: ГУУ, 2015. - 332 c. - C. 87-91.

8. Саватье P. Теория обязательств [Текст] / Р. Саватье. М.: Прогресс, 1972. - С. 25, 26.

9. Сазанова С.Л. Институциональная теория организаций [Текст] / С.Л. Сазанова // Вестник Университета (Государственный университет управления). - 2015. № 8. - C. 61-66.

10. Салов Н.Н. Изобретения. Как мы смотрим на изобретения и как должны бы на них смотреть [Текст] / Н.Н. Салов. - СПб.: Славянская печатня, Гороховая, № 46, 15 января 1877 г. // Советская Россия. - 1999. 29 июля. - С. 2.
Applications: Proceedings of the fourth International Conference. Moscow, State University of Management Publ., 2015, pp. 87-91. (in Russian)

8. Savatier P. Theory of obligations. Moscow, 1972, pp. 25-26. (in Russian)

9. Sazanova S. Institutional theory of organizations. Bulletin of the University (State University of Management). 2015, V. 8, pp. 61-66. (in Russian)

10. Salov N. Inventions. As we look at the invention and how it should be to look at them. St.-Petersburgg, 1877, V. 46, January 15th. Soviet Russia. 1999. 29 July, p. 2. (in Russian) 